\title{
A Novel, Simplified Ex Vivo Method for Measuring Water Exchange Performance of Heat and Moisture Exchangers for Tracheostomy Application
}

\author{
Cindy van den Boer MD, Sara H Muller PhD, Andrew D Vincent PhD, Klaus Züchner PhD, \\ Michiel WM van den Brekel MD PhD, and Frans JM Hilgers MD PhD
}

\begin{abstract}
BACKGROUND: Breathing through a tracheostomy results in insufficient warming and humidification of inspired air. This loss of air-conditioning can be partially compensated for with the application of a heat and moisture exchanger (HME) over the tracheostomy. In vitro (International Organization for Standardization [ISO] standard 9360-2:2001) and in vivo measurements of the effects of an HME are complex and technically challenging. The aim of this study was to develop a simple method to measure the ex vivo HME performance comparable with previous in vitro and in vivo results. METHODS: HMEs were weighed at the end of inspiration and at the end of expiration at different breathing volumes. Four HMEs (Atos Medical, Hörby, Sweden) with known in vivo humidity and in vitro water loss values were tested. The associations between weight change, volume, and absolute humidity were determined using both linear and non-linear mixed effects models. RESULTS: The rating between the 4 HMEs by weighing correlated with previous intratracheal measurements $\left(R^{2}=0.98\right)$, and the ISO standard $\left(R^{2}=0.77\right)$. CONCLUSIONS: Assessment of the weight change between end of inhalation and end of exhalation is a valid and simple method of measuring the water exchange performance of an HME. Key words: heat and moisture exchanger; humidity; respiration; tracheostomy; total laryngectomy. [Respir Care 2013;58(9):14491458. () 2013 Daedalus Enterprises]
\end{abstract}

\section{Introduction}

Total laryngectomy is the treatment of choice for advanced (T4) laryngeal cancer and for recurrent disease after prior organ preservation treatment. ${ }^{1}$ This surgical procedure results in breathing through a mandatory perma-

Drs van den Boer and van den Brekel are affiliated with the Department of Head and Neck Oncology and Surgery; Dr Muller is affiliated with the Department of Clinical Physics and Instrumentation; and Dr Vincent is affiliated with the Department of Biometrics, The Netherlands Cancer Institute, Antoni van Leeuwenhoek Hospital, Amsterdam, The Netherlands. Dr Züchner is affiliated with the Medical Technical Service, University Medical Center, Georg-August University, Göttingen, Germany. Dr van den Brekel is also affiliated with the Institute of Phonetic Sciences; and Drs van den Brekel and Hilgers are affiliated with the Department of Otorhinolaryngology, Academic Medical Center, University of Amsterdam, Amsterdam, The Netherlands.

Dr van den Boer presented a version of this paper at the 8th International Conference on Head and Neck Cancer, held by the American Head and Neck Society, in Toronto, Ontario, Canada, July 21-25, 2012. nent tracheostoma, which profoundly alters respiratory physiology. The bypass of the upper airways leads to insufficient warming and humidification of the inspired air. Consequently, patients develop pulmonary problems such

\footnotetext{
Supplementary material related to this paper is available at http:// www.rcjournal.com.

This study was partly funded by an unrestricted research grant from Atos Medical, the manufacturer of the tested heat and moisture exchangers. Atos Medical had no involvement in the study design, data collection, analysis, or interpretation; the writing or editing; or the decision to submit the manuscript for publication. The authors have disclosed no other conflicts of interest.
}

Correspondence: Frans JM Hilgers MD PhD, Head and Neck Oncology and Surgery, The Netherlands Cancer Institute, Antoni van Leeuwenhoek Hospital, Plesmanlaa 121, Amsterdam 1066CX Netherlands. E-mail: f.hilgers@nki.nl.

DOI: $10.4187 /$ respcare.02369 
as mucus hypersecretion and frequent involuntary coughing, and become more susceptible to respiratory infections. ${ }^{2,3}$ Also, breathing through a temporary tracheostomy results in insufficient warming and humidification of inspired air. Compensation for the loss of air-conditioning can be achieved by application of a heat and moisture exchanger (HME) over the tracheostoma. ${ }^{4}$ HMEs are passive humidifiers: during exhalation, water is retained onto the core material of the HME, and during inhalation this water is released again into inspired air. The core material of an HME consists of foam, paper, or other substances, usually impregnated with hygroscopic salt to increase the water retaining capacity. Simultaneously to the exchange of water, HMEs store and release heat during the breathing cycle. 5,6 Use of an HME after laryngectomy has proven to significantly reduce pulmonary complaints and to improve quality of life. ${ }^{4,7-9}$ Therefore, these medical devices are currently considered as mandatory therapeutic and rehabilitative measures for laryngectomized patients.

\section{See the Related Editorial on Page 1559}

Presently, a wide range of HMEs are commercially available, and for medical professionals it is not easy to judge the differences in performance of the various HMEs. Some manufacturers provide water loss values for their HMEs according to the International Organization for Standardization (ISO) standard 9360-2:2001, but this specification is not universally available. Moreover, water loss values are not easily and intuitively translated into clinical benefits, as higher water loss correlates with a less effective HME performance. An additional issue is that the 24-hour ISO measurements require complex and validated machinery, and slight differences in setup specifications (eg, calibration) of these measurements can lead to considerable outcome variations between laboratories. ${ }^{10,11}$ Alternatively, clinical decision-making could be based on in vivo measurements of the HME effect on tracheal climate.

Since direct intra-tracheal humidity measurements are technically complicated, most studies have opted to sample air from the trachea and to analyze this sample with an external fast humidity sensor. In such measurements extreme care is required to avoid loss of water vapor due to condensation in the sampling tube. ${ }^{12,13}$ No commercial equipment is available for these challenging measurements, and experience has shown that custom-built equipment is difficult to develop and maintain. ${ }^{12,13}$ Moreover, only a minority of available HMEs thus far have been analyzed both in vitro and in vivo. ${ }^{12-15}$ Therefore, an easy method for assessing HME performance using commercially available equipment could be very useful for medical professionals. Also, for HME development a universally avail-

\section{QUICK LOOK}

\section{Current knowledge}

Humidification of inspired gases following laryngectomy can be achieved with heated humidification or a heat and moisture exchanger (HME). The performance of heat and moisture exchangers is variable and can be altered by air leaks or the addition of oxygen. The measurement of delivered humidity in a laryngectomy patient is difficult.

\section{What this paper contributes to our knowledge}

Measuring the weight change of an HME between the end of inhalation and the end of exhalation is a reliable measure of HME performance, comparing favorably to in vitro measurements conducted per International Organization for Standardization standard 9360-2:2001, and to in vivo measurements from a previous study. The weight-change method is simpler and does not require expensive laboratory sensors and equipment.

able tool is required for comparing newly designed and existing HMEs next to clinical feasibility studies.

Since an HME stores and releases water with each inhalation and exhalation, the HME gains and loses weight during breathing. The amount of water, and therefore the weight change, depends on the breathing volume. We postulated that this change of weight could be an alternative measure for HME performance. For weight measurements a suitable balance could be used, and for volume assessment a commercial spirometer should be sufficient. The purpose of this study was to establish whether the weight change of an HME between end of inhalation and end of exhalation could be a measure of HME performance comparable to in vitro ISO measurements and previous in vivo measurements.

\section{Methods}

The study was approved by our protocol review board, and informed consent was obtained from all volunteers.

\section{HME Devices}

Two commercially available HME devices and 2 prototype devices (all by Atos Medical, Hörby, Sweden) were tested in this study, identical to the HME devices used in the recent in vivo study of Scheenstra et al. ${ }^{6}$ HME specifications of water loss values according to the ISO standards and the in vivo absolute humidity $(\mathrm{AH})$ values according to Scheenstra et al are shown in Table 1. 


\section{A Novel, Simplified Ex Vivo Method for Measuring Water Exchange Performance}

Table 1. Water Loss and Absolute Humidity Data: In Vitro ISO Values and In Vivo End-Inspiratory Absolute Humidity, and HME Effect*

\begin{tabular}{|c|c|c|c|}
\hline & $\begin{array}{c}\text { Water Loss at } \mathrm{V}_{\mathrm{T}} 1 \mathrm{~L} \text { and } \\
\mathrm{AH}_{\text {amb-ref }} 0 \mathrm{mg} / \mathrm{L} \mathrm{H}_{2} \mathrm{O} \\
\mathrm{mg} \mathrm{H} \mathrm{H}_{2} \mathrm{O} / \mathrm{L} \\
\text { (ISO } 9360-2: 2001 \text { ) }\end{array}$ & $\begin{array}{c}\mathrm{AH}_{\text {insp }} \text { at } \mathrm{V}_{\mathrm{T}} 0.5 \mathrm{~L} \text { and } \\
\mathrm{AH}_{\text {amb-ref }} 5 \mathrm{mg} / \mathrm{L} \mathrm{H} \mathrm{H}_{2} \mathrm{O} \\
\mathrm{mg} \mathrm{H} \mathrm{H}_{2} \mathrm{O} / \mathrm{L} \\
\left(\text { Scheenstra et } \mathrm{al}^{6}\right)\end{array}$ & $\begin{array}{c}\mathrm{AH}_{\text {insp }} \text { with } \mathrm{HME} \text { vs } \\
\mathrm{AH}_{\text {insp }} \text { without } \mathrm{HME} \dagger \\
\text { at } \mathrm{V}_{\mathrm{T}} 0.5 \mathrm{~L} \text { and } \\
\mathrm{AH}_{\text {amb-ref }} 5 \mathrm{mg} / \mathrm{L} \mathrm{H}_{2} \mathrm{O} \\
\mathrm{mg} / \mathrm{L} \mathrm{H}_{2} \mathrm{O} \\
(\text { Scheenstra et al } \\
\end{array}$ \\
\hline Without HME & NA & 17.7 & NA \\
\hline Provox HiFlow & 25.4 & 20.4 & 2.7 \\
\hline Provox Normal & 23.7 & 21.6 & 3.8 \\
\hline Prototype Lplus & 24.0 & 22.2 & 4.5 \\
\hline Prototype Rplus & 21.5 & 24.8 & 7.0 \\
\hline \multicolumn{4}{|c|}{$\begin{array}{l}\text { * The Provox HiFlow was tested in an in vivo study, }{ }^{20} \text { whereas the prototype Rplus and Lplus heat and moisture exchangers (HMEs) were tested in an in vitro study, }{ }^{6} \text { so the end-inspiratory absolute } \\
\text { humidity ( } \mathrm{AH}_{\text {insp }} \text { ) of the Provox HiFlow is converted using the corresponding difference between the Provox HiFlow and Provox Normal (reference value) for the } 2 \text { datasets. The in vivo data are } \\
\text { normalized to the reference ambient absolute humidity ( } \mathrm{AH}_{\text {amb-ref }} \text { ) of } 5 \mathrm{mg} / \mathrm{L} \mathrm{H}_{2} \mathrm{O} \text { using equation } 1 \text { (see text). } \\
\dagger \text { Intratracheal increase of end-inspiratory absolute humidity with versus without heat and moisture exchanger (HME). } \\
\text { ISO = International Organization for Standardization standard } \\
\mathrm{V}_{\mathrm{T}}=\text { tidal volume } \\
\mathrm{AH} \mathrm{H}_{\text {amb-ref }}=\text { reference ambient absolute humidity } \\
\mathrm{AH} \text { insp }=\text { end-inspiratory absolute humidity } \\
\mathrm{NA}=\text { not applicable }\end{array}$} \\
\hline
\end{tabular}

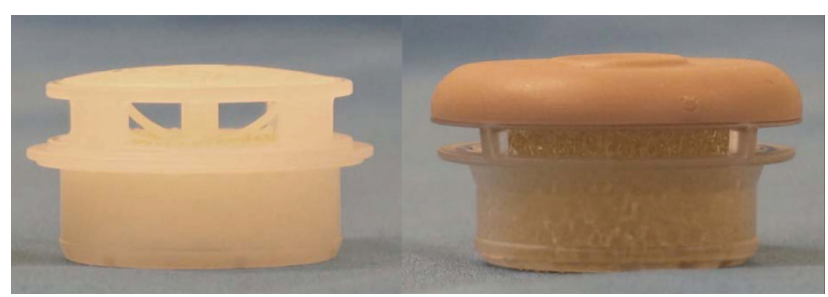

Fig. 1. Left: Provox Normal, in which the closure mechanism is a plastic spring. Right: Rplus, in which the closure mechanism is the foam.

The 2 commercially available HMEs were the Provox Normal and the Provox HiFlow. The prototype versions are the Rplus and its lower resistance version the Lplus. These prototypes have a different closure mechanism and more foam material, in order to improve performance (Fig. 1)

\section{Humidity and Breathing Volume Measurement}

Measurements were performed with the test configuration shown in Figure 2. A healthy volunteer (female, 29 years of age, first author $\mathrm{CvdB}$ ) breathed through a spirometer (Flowhead MLT300 ADInstruments, Oxfordshire, United Kingdom). The other side of the spirometer was connected to a T-shaped tube. Inside this T-tube humidity was measured with a fast heated capacitive hygrometer that measures the $\mathrm{AH}$ ( $\mathrm{AH}$ sensor) with a response time of $0.1-0.2 \mathrm{~s} .{ }^{16}$ The AH sensor was calibrated as described previously, using a reference humidity sensor (Testo, Almere, The Netherlands). Inaccuracy of the AH after this calibration is $<5 \% .^{5,13}$ At the far end of the T-tube an HME was connected. The dead space of the

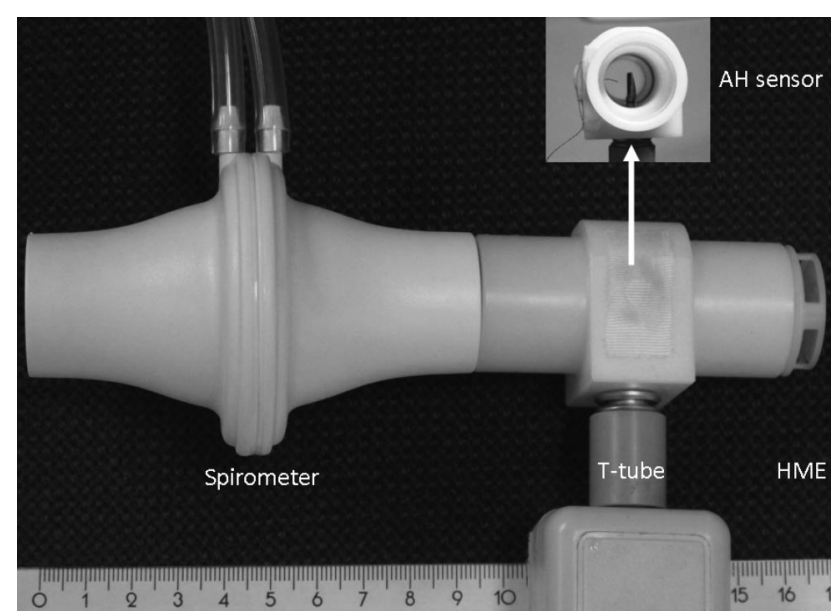

Fig. 2. Test configuration. The spirometer is connected to a T-tube that contains the absolute humidity $(\mathrm{AH})$ sensor, and T-tube is connected to the heat and moisture exchanger (HME). The ruler is in centimeters.

T-tube is $30 \mathrm{~mL}$, and the dead space of the spirometer flowhead is $70 \mathrm{~mL}$, according to the manufacturer's manual.

The spirometer was calibrated before each use, and the resulting data were corrected for baseline and volume drift according to the manufacturer's recommendations. Volume drift is caused mainly by the increased volume of the warmer and moister exhaled air, so drift correction was applied only to the exhaled volumes. Integrating the flow over the duration of the breath yields the observed breathing volume. Spirometer data were recorded and analyzed with data acquisition software (Powerlab, ADInstruments, Oxfordshire, United Kingdom).

Humidity values were registered and saved with data acquisition software (Acquis 2.8, Anesthesie-Technik, 
Amsterdam, The Netherlands) and exported to a spreadsheet (Excel, Microsoft, Redmond, Washington). The ambient humidity and temperature were monitored with a commercial, calibrated humidity sensor (Testo, Almere, The Netherlands). Body temperature of the volunteer was monitored with an electronic aural thermometer (Genius2, Kendall, Covidien, Mansfield, Massachusetts).

\section{Weight Measurement}

Weight was measured with a micro balance (MC210P, Sartorius, Göttingen, Germany). Stability of the balance and of the measurement procedure was monitored by repeated measurements of a calibration weight. Accuracy and repeatability were within $0.1 \mathrm{mg}$.

Each HME was placed in a $35 \times 19 \mathrm{~mm}$ airtight cylindrical box immediately after inhalation or exhalation, to prevent evaporation into the ambient air during the weight measurements. The time required to remove the HME from the T-tube and place it in the box was $3 \pm 1 \mathrm{~s}$. Control measurements of HMEs not enclosed in the box showed that weight loss due to evaporation was $<5 \%$ of the weight change of the HME in the first 3 seconds. Error in the weight measurements due to the variation in time to placement in the box was $<2 \%$ of the weight change. During reconditioning of the HME (see below), in between weight measurements, the box was left open to prevent buildup of condensation inside the box.

Preferably, measurements should be performed under clean-room conditions to prevent contamination with, for instance, dust particles. Because this was not possible in our laboratory, we used optimal hygienic measures instead. Aluminum foil was used to keep the surface around the balance as clean as possible, and the empty boxes were weighed before and after each experiment to check for contamination. If contamination occurred, the measurement sequence was excluded from analysis.

\section{Preparation of the HMEs}

The foam in the tested HMEs is impregnated with a hygroscopic salt $\left(\mathrm{CaCl}_{2}\right)$. The amount of water absorbed by the $\mathrm{CaCl}_{2}$ depends primarily on the ambient relative humidity. ${ }^{17}$ Therefore the HMEs were kept overnight at a constant relative humidity of $40-45 \%$ and room temperature of $20-22^{\circ} \mathrm{C}$. To minimize drift during the measurements, the HMEs were conditioned toward equilibrium water saturation at the start of the measurement sequence, by continuous at-rest breathing by the volunteer, at $14.5 \pm 0.5$ breaths $/ \mathrm{min}$. For each HME the length of the conditioning period required for equilibrium water saturation (stable weight) was determined by verifying the weight increase over time (10-20 min).

\section{Measurement Protocol}

After conditioning the HME, a sequence of 25 weight measurements was performed, alternatingly at the end of inhalation and at the end of exhalation. To obtain measurements at a range of breathing volumes, the volunteer breathed with 3 different breathing patterns: 13 measurements with at-rest breathing (tidal volume), 6 measurements with deep breathing, and 6 measurements with shallow breathing. Before each weight measurement a short period of tidal breathing (at least 5 breathing cycles) was used to recondition the HME, immediately followed by an inhalation or exhalation of the prescribed breathing pattern. One breath (measurement) was defined as one inhalation or one exhalation. The breathing cycle was defined as the sum of one inhalation and one exhalation. The absolute humidity was measured at the end of inhalation, just before removal of the HME (the end-inspiratory $\mathrm{AH}$, $\left.\mathrm{AH}_{\mathrm{insp}}\right)$. The duration of one measurement sequence was between 40 and 50 min.

With all 4 HMEs the measurement sequence was performed by the same volunteer. To assess intra-individual variation, 5 additional HMEs of one type (Provox Normal) were measured 11 times (weight, volume, and $\mathrm{AH}$ ) during at-rest breathing. To assess inter-individual variation, one measurement sequence of 25 measurements with a Provox Normal was performed by 5 additional healthy volunteers (mean age 36 y, 3 males and 2 females). To establish the baseline HME capacity of the test set configuration (spirometer and T-shaped tube), 14 additional humidity measurements were performed without HME by the volunteer.

\section{Data Normalization}

The measured end-inspiratory $\mathrm{AH}\left(\mathrm{AH}_{\text {insp-meas }}\right)$ depends on the ambient $\mathrm{AH}\left(\mathrm{AH}_{\mathrm{amb}}\right) \cdot{ }^{15-18} \mathrm{AH}_{\text {insp-meas }}$ cannot be lower than $\mathrm{AH}_{\mathrm{amb}}$, and if $\mathrm{AH}_{\mathrm{amb}}$ is equal to the alveolar $\mathrm{AH}\left(\mathrm{AH}_{\mathrm{alv}}\right)$, the $\mathrm{AH}_{\text {insp-meas }}$ will be equal to $\mathrm{AH}_{\mathrm{alv}}$.

In order to compare measurements on different days with varying $\mathrm{AH}_{\mathrm{amb}}$ (measured in this study), the measured $\mathrm{AH}_{\text {insp-meas }}$ was converted into a normalized $\mathrm{AH}_{\text {insp }}$ at the reference ambient humidity $\left(\mathrm{AH}_{\mathrm{amb}-\mathrm{ref}}\right)$, chosen to be $5 \mathrm{mg} / \mathrm{L}$, using the following equation (comparable to Fig. 2 in Wilkes 200418):

$$
\begin{array}{r}
\mathrm{AH}_{\text {insp }} \text { at } \mathrm{AH}_{\text {amb-ref }}=\mathrm{AH}_{\text {amb-ref }}+\left(\mathrm{AH}_{\text {insp-meas }}-\mathrm{AH}_{\text {amb }}\right) \\
\times\left(\mathrm{AH}_{\text {alv }}-\mathrm{AH}_{\text {amb-ref }}\right) /\left(\mathrm{AH}_{\text {alv }}-\mathrm{AH}_{\mathrm{amb}}\right)
\end{array}
$$

The equation is a simplification that normalizes only for the actual measured $\mathrm{AH}_{\mathrm{amb}}$ variation, and does not account for any other dependencies of $\mathrm{AH}_{\text {insp }}$ such as dead space. 


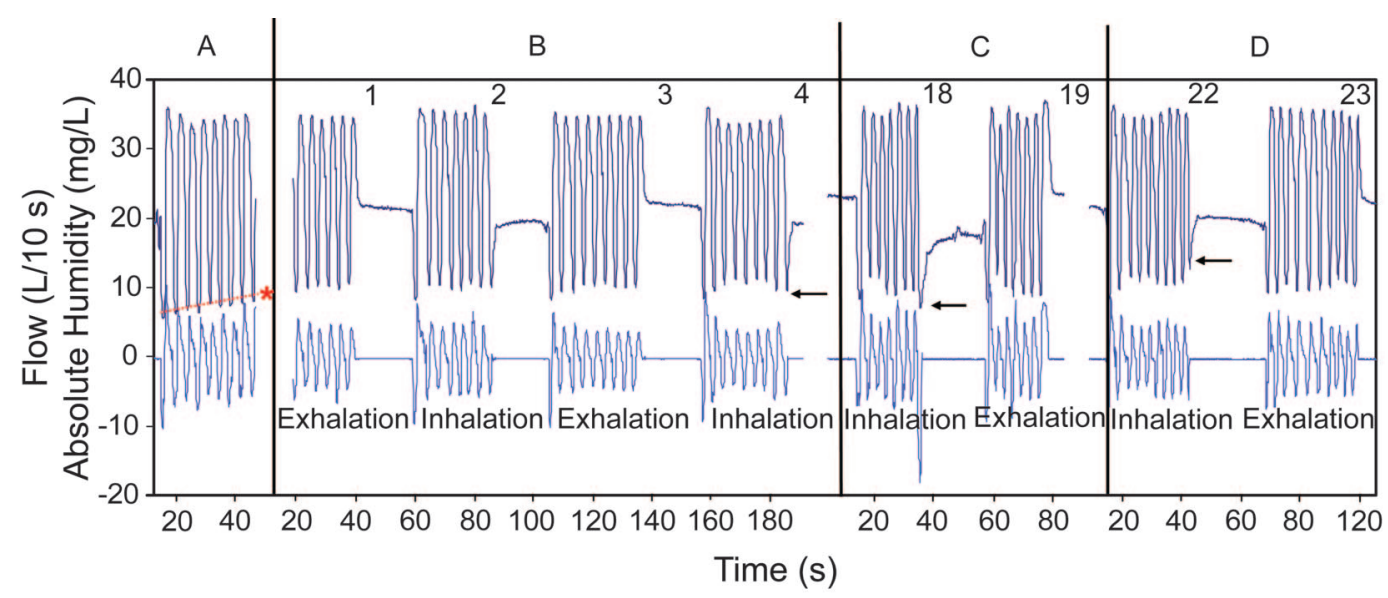

Fig. 3. Raw data trace of absolute humidity and breathing air flow with the prototype Lplus heat and moisture exchanger (HME). Note that the maximum values do not show an immediate conditioning effect, because the humidity sensor is located upstream from the HME. Only during inhalation is the humidity sensor downstream from the HME and able to register the instantaneous impact of the HME on the absolute humidity, so only the end-inspiratory humidity measurements were analyzed. A: Start of the HME conditioning, showing the increasing humidity (asterisk). B: At-rest, tidal-volume breathing (measurements 1-4). C: Deep breathing (measurements 18 and 19 ). D: Shallow breathing (measurements 22 and 23).

For $\mathrm{AH}_{\text {alv }}$ the saturation humidity at body temperature of the volunteer was used (using the equation in Zuur et $\mathrm{al}^{19}$ and at http://www.humidity-calculator.com/index. php).

Similarly, weight change $(\Delta \mathrm{W})$ will also depend on the ambient humidity. The measured $\Delta \mathrm{W}$ was normalized to a normalized $\Delta \mathrm{W}$ at $\mathrm{AH}_{\text {amb-ref }}$ using the equation:

$\Delta \mathrm{W}$ at $\mathrm{AH}_{\text {amb-ref }}=$ measured $\Delta \mathrm{W}$

$$
\times\left(\mathrm{AH}_{\mathrm{alv}}-\mathrm{AH}_{\mathrm{amb}-\mathrm{ref}} /\left(\mathrm{AH}_{\mathrm{alv}}-\mathrm{AH}_{\mathrm{amb}}\right)\right.
$$

Using the body temperature to calculate $\mathrm{AH}_{\text {alv }}$ is justified only when $\mathrm{AH}_{\text {alv }}$ is much larger than both $\mathrm{AH}_{\text {amb-ref }}$ and $\mathrm{AH}_{\mathrm{amb}}$. Normalization for body temperature of the volunteers could have been done in a similar way, but was not performed, because the volunteer's body temperature was constant within $0.3^{\circ} \mathrm{C}$ (the corresponding error in the weight change is $<2 \%$ ).

\section{Statistical Methods}

Associations. The association between breath volume and both HME weight and $\mathrm{AH}$ were modeled using mixed effects regression. Given the different measurement protocols, only the change in HME weight was available, so 2 different models were constructed. Scatter plots suggested a linear relationship between weight change and log-transformed breath volume, so the weight change mixed effects model included the log-transformed volume, HME type, and their interaction as predictor variables. Random intercepts were included for each measurement period (see the supplementary materials at http://www.rcjournal.com).
For AH the scatter plots suggested an exponential decay with non-zero asymptote. Consequently, the association between $\mathrm{AH}_{\text {insp }}$ and inspiratory breathing volume was determined using an exponential-decay, nonlinear, least squares regression. The $\mathrm{AH}_{\text {insp }}$ values were the outcome with initial AH levels set at the end-expiratory humidity values from the previous breath. The exponential decay asymptote, initial intercept, and decay rate were allowed to vary with HME type (see the supplementary materials at http://www.rcjournal.com).

Repeatability. The intra-individual variation of the Provox Normal during tidal-breathing was measured with one volunteer $(\mathrm{CvdB})$ at 6 distinct assessment periods. Systematic differences across the assessment periods were tested for using Kruskal-Wallis tests for 3 parameters: $\mathrm{AH}_{\text {insp }}$, end-expiratory $\mathrm{AH}$, and the ratio of weight change to breathing volume.

To assess the inter-individual variation of the Provox Normal, weight and corresponding volume measurements were taken from 6 volunteers. In the weight-change versus (log-transformed) breath-volume linear mixed effects model, random intercepts and slopes were included per individual. The inter- and intra-individual variations were assessed in the weight-change model at breathing volumes of $0.5 \mathrm{~L}$ and $1.0 \mathrm{~L}$.

Validation. We compared the estimated $\mathrm{AH}_{\text {insp }}$ values at inspiratory volume $0.5 \mathrm{~L}$ from the present study to previously published in vivo results. The correlation coefficient was determined from a weighted linear regression using inverse variances. Similarly, we compared the estimated 

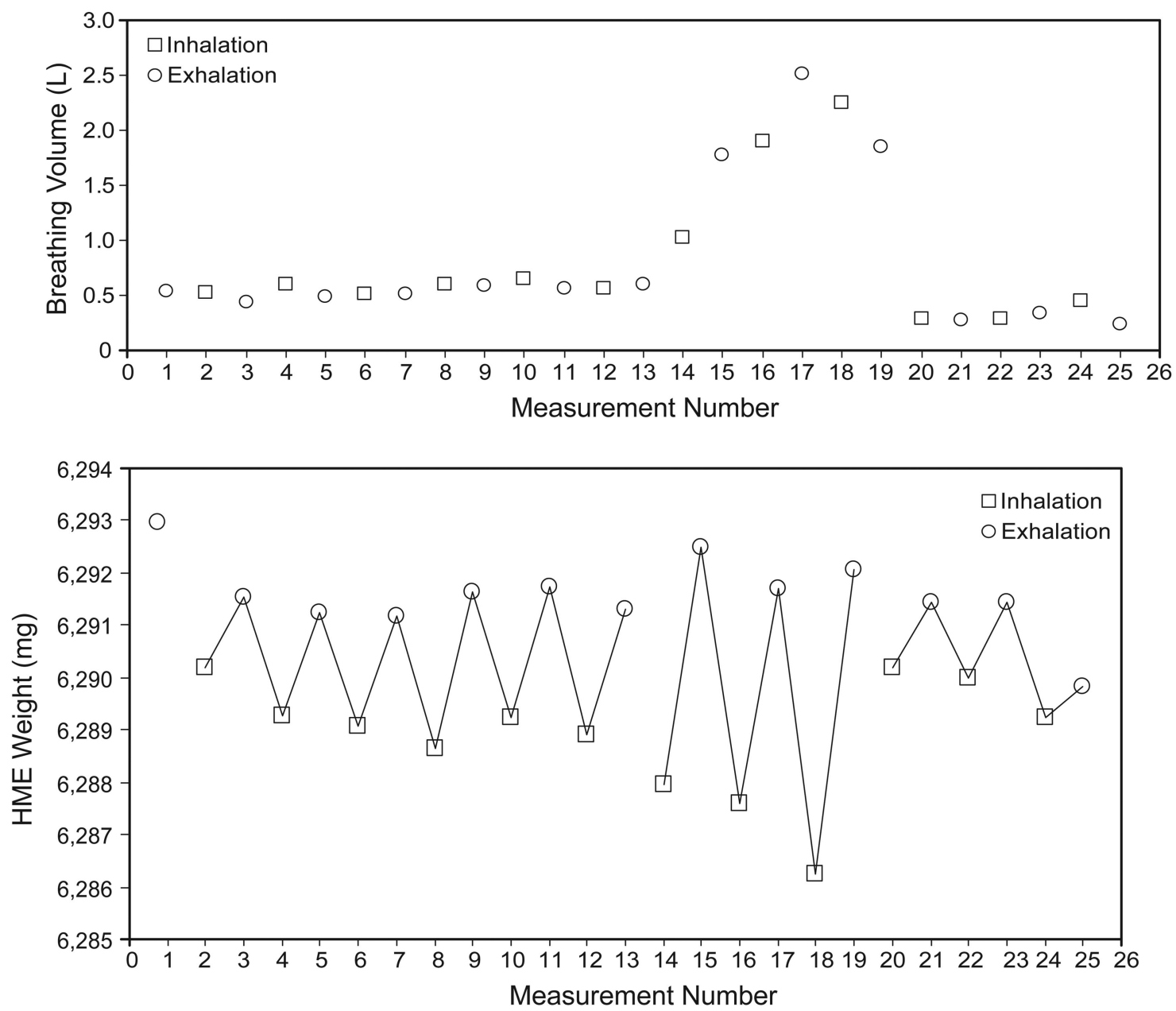

Fig. 4. Example measurement sequence with the prototype Lplus heat and moisture exchanger. The line segments connecting the weight measurements represent the weight changes used in the analysis (see text). The measurement numbers correspond to the numbers in Figure 3.

weight changes at breathing volume of $1.0 \mathrm{~L}$ to ISO water loss at $1.0 \mathrm{~L}$.

\section{Results}

Figure 3 shows in detail how the measurement sequence was performed. The figure shows parts of the raw data trace of the $\mathrm{AH}$ sensor (upper trace) and the spirometer flow sensor (lower trace) for the prototype Lplus. Section A shows the first breaths of the HME conditioning period, where the $\mathrm{AH}_{\text {insp }}$ slowly increases, due to the increasing moistening of the inspired air by the HME (asterisk in Fig. 3). Sections B, C, and D show examples of measurements during the 3 different breathing volumes (tidal, deep, and shallow breathing). In the raw data trace in Figure 3 the difference in $\mathrm{AH}_{\text {insp }}$ for the different breathing levels can be seen: $\mathrm{AH}_{\text {insp }}$ at the end of deep inhalation 18 is lower than $\mathrm{AH}_{\text {insp }}$ during the tidal breaths, which in turn are lower than $\mathrm{AH}_{\text {insp }}$ during shallow inhalation 22 (see the arrows Fig. 3).

Figure 4 shows the volume and weight measurements of an example sequence ( 25 measurements) with the prototype Lplus. The numbers on the $\mathrm{X}$ axis correspond to the numbers in Figure 3 above the raw AH trace. From the observed weights, 21 weight changes of the HME were calculated between the maximum and minimum weights (end of exhalation versus end of inhalation) and are shown by the line segments in the weight graph in Figure 4. The average volume was calculated for corresponding consecutive weight measurements. Weight changes between inhalations and exhalations belonging to different breathing types were discarded, as was the first weight measurement of each measurement sequence, because these are systematically higher due to the different conditioning history (see first data point in the weight graph in Fig. 4). 


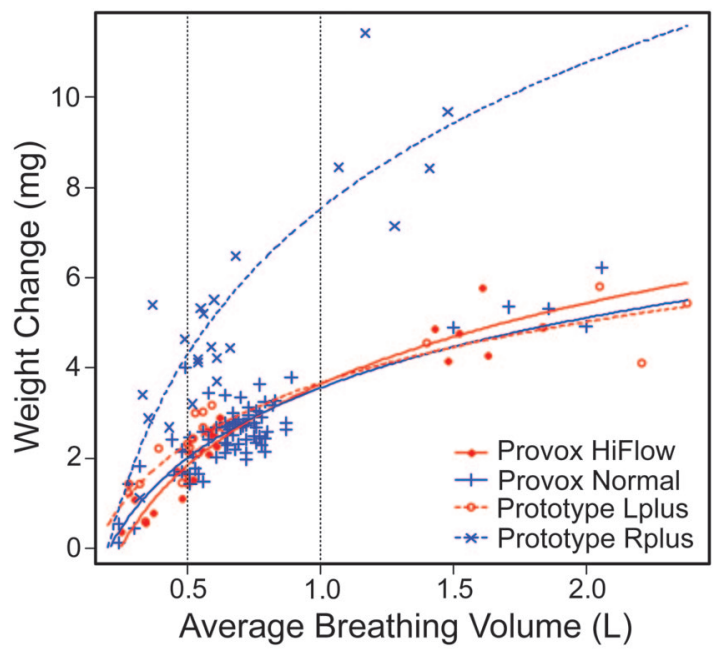

Fig. 5. Weight change as function of average breathing volume, normalized to the reference ambient absolute humidity $\left(\mathrm{AH}_{\text {amb-ref }}\right.$, $5 \mathrm{mg} / \mathrm{L}$ ). For each heat and moisture exchanger (HME) model, 21 weight differences are shown, except for Provox Normal, for which the repeatability measurement points (40) are also depicted. The vertical dashed lines indicates the weight changes at average breathing volumes of $0.5 \mathrm{~L}$ and $1.0 \mathrm{~L}$ per HME (see Table 2). The parameters of the fit are given in the supplementary materials at http://www.rcjournal.com. The offset of the estimated model fits on the average breathing volume axis shows the impact of the dead space. During inhalation the HME weight decrease starts immediately, but during exhalation the weight begins to increase after the air in the dead space has passed the HME. Therefore, the offset on the average breathing volume axis is equal to half of the combined dead space of T-tube, spirometer, and volunteer.

Weight change as a function of average breathing volume is shown in Figure 5 for all 4 HME types. All measurements were normalized to the $\mathrm{AH}_{\text {amb-ref }}$ of $5 \mathrm{mg} / \mathrm{L}$ (the range of measured $\mathrm{AH}_{\mathrm{amb}}$ was $7.22-9.62 \mathrm{mg} / \mathrm{L}$ ). For each HME the estimated model fit is shown.

The model fit of $\mathrm{AH}_{\text {insp }}$ as a function of inspiratory breathing volume is shown in Figure 6 for 21 HME measurements per HME model, and for 14 measurements made without HME. These measurements were also normalized to the $\mathrm{AH}_{\text {amb-ref }}$ of $5 \mathrm{mg} / \mathrm{L}$.

In Figure 5 the weight changes at average breathing volumes of $0.5 \mathrm{~L}$ and $1.0 \mathrm{~L}$, and in Figure $6 \mathrm{AH}_{\text {insp }}$ values at an average breathing volume of $0.5 \mathrm{~L}$ are marked per HME (vertical dashed lines). These values are summarized in Table 2, together with the differences relative to the Provox Normal. Values at $0.5 \mathrm{~L}$ were required for comparison with the previously reported in vivo measurements in patients, with an average breathing volume of $0.5 \mathrm{~L} .{ }^{20}$ For comparison with the ISO standard, weight changes at a volume of $1.0 \mathrm{~L}$ were required.

Repetitions of the Provox Normal at tidal volume breathing showed no systematic differences across the measurement periods for AH (inspiration $P=.18$, expiration

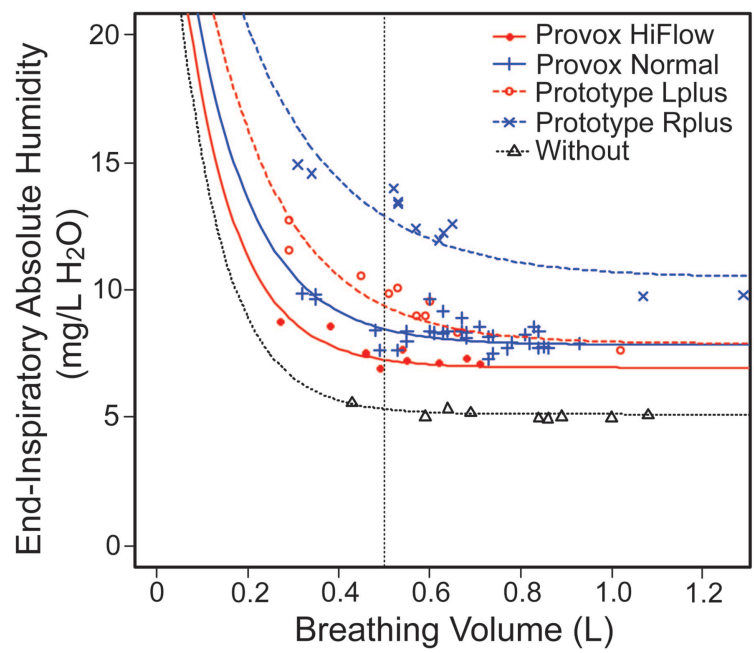

Fig. 6. End-inspiratory absolute humidity $\left(\mathrm{AH}_{\mathrm{insp}}\right)$ as a function of inspiratory breathing volume, normalized to the reference ambient absolute humidity $\left(\mathrm{AH}_{\text {amb-ref }}, 5 \mathrm{mg} / \mathrm{L}\right)$. The $21 \mathrm{AH}_{\text {insp }}$ values corresponding to the weight changes shown in Figure 5 and the 14 measurements without HME were used to calculate the fits of the model. Due to the chosen scale on the horizontal axis, not all measured points are visible. The vertical dashed line indicates the $\mathrm{AH}_{\text {insp }}$ per $\mathrm{HME}$ at the $0.5 \mathrm{~L}$ inspiratory volume (see Table 2). The parameters of the fit are given in the supplementary materials at http://www.rcjournal.com.

$P=.12)$ or the ratio of weight change to volume $(P=.58)$. The inter-individual variation for the 6 volunteers at breathing volumes of $0.5 \mathrm{~L}$ and $1.0 \mathrm{~L}$ were $0.45 \mathrm{mg} / \mathrm{L}$ and $0.78 \mathrm{mg} / \mathrm{L}$, respectively, and the intra-individual variation was $0.18 \mathrm{mg} / \mathrm{L}$ for both breathing volumes. Consequently, the differences between the Rplus and the other HME models for a single observer (see Table 2) exceed the estimated $95 \% \mathrm{CI}$ upper limits of 1.34 at $0.5 \mathrm{~L}$ and 2.22 at $1.0 \mathrm{~L}$, when inter-individual variation is included.

Figure 7 compares the in vivo $\mathrm{AH}_{\text {insp }}$ measurements in subjects from Scheenstra et $\mathrm{al}^{6}$ to the values obtained in the present study at a volume of $0.5 \mathrm{~L}$ (see Table 2) and the $\mathrm{AH}_{\text {amb-ref }}$ of $5 \mathrm{mg} / \mathrm{L}$. Comparison of the HME weight change in the present study and the ISO standards is shown in Figure 8. The weight changes at a volume of $1.0 \mathrm{~L}$ from Table 2 are normalized to the standard ISO humidity conditions of $0 \mathrm{mg} / \mathrm{L}$ using equation 2 .

\section{Discussion}

This study shows that HME performance can be determined by measuring the weight difference between endinspiration and end-expiration, using a regular balance and a standard spirometer. The results correlate well with earlier in vivo measurements made with complex, custombuilt equipment to measure intra-tracheal humidity, and with in vitro values provided by the manufacturer, based on 24-hour, ISO standard 9360-2:2001 assessments. 


\section{A Novel, Simplified Ex Vivo Method for Measuring Water Exchange Performance}

Table 2. HME Performance in End-Inspiratory Absolute Humidity and HME Weight Change, Normalized for Reference Ambient Humidity of $5 \mathrm{mg} / \mathrm{L}$

\begin{tabular}{|c|c|c|c|}
\hline & $\begin{array}{c}\mathrm{AH}_{\mathrm{insp}} \\
\text { at } \mathrm{V}_{\mathrm{T}} 0.5 \mathrm{~L} \\
\text { mean } \pm \text { standard error } \\
\mathrm{mg} / \mathrm{L}\end{array}$ & $\begin{array}{l}\text { HME Weight Change } \\
\text { at } \mathrm{V}_{\mathrm{T}} 0.5 \mathrm{~L} \\
\text { mean } \pm \text { standard error } \\
\mathrm{mg}\end{array}$ & $\begin{array}{c}\text { HME Weight Change } \\
\text { at } \mathrm{V}_{\mathrm{T}} 1.0 \mathrm{~L} \\
\text { mean } \pm \text { standard error } \\
\mathrm{mg}\end{array}$ \\
\hline Without HME & $5.3 \pm 0.1$ & NA & NA \\
\hline Provox HiFlow & $7.3 \pm 0.11$ & $1.8 \pm 0.15$ & $3.6 \pm 0.19$ \\
\hline Difference between Provox HiFlow and Provox Normal & $-1.2(P<.001)$ & $-0.2(P=.36)$ & $0.1(P=.21)$ \\
\hline Provox Normal (reference) & $8.5 \pm 0.11$ & $2.0 \pm 0.10$ & $3.6 \pm 0.11$ \\
\hline Prototype Lplus & $9.4 \pm 0.19$ & $2.3 \pm 0.15$ & $3.7 \pm 0.17$ \\
\hline Difference between Prototype Lplus and Provox Normal & $0.9(P<.001)$ & $0.3(P=.09)$ & $0.1(P=.19)$ \\
\hline Prototype Rplus & $12.9 \pm 0.28$ & $4.3 \pm 0.16$ & $7.5 \pm 0.20$ \\
\hline Difference between Prototype Rplus and Provox Normal & $4.4(P<.001)$ & $2.3(P<.001)$ & $3.9(P<.001)$ \\
\hline $\begin{array}{l}P \text { values are for comparison with Provox Normal (reference). } \\
\mathrm{V}_{\mathrm{T}}=\text { tidal volume } \\
\mathrm{NA}=\text { not applicable }\end{array}$ & & & \\
\hline
\end{tabular}

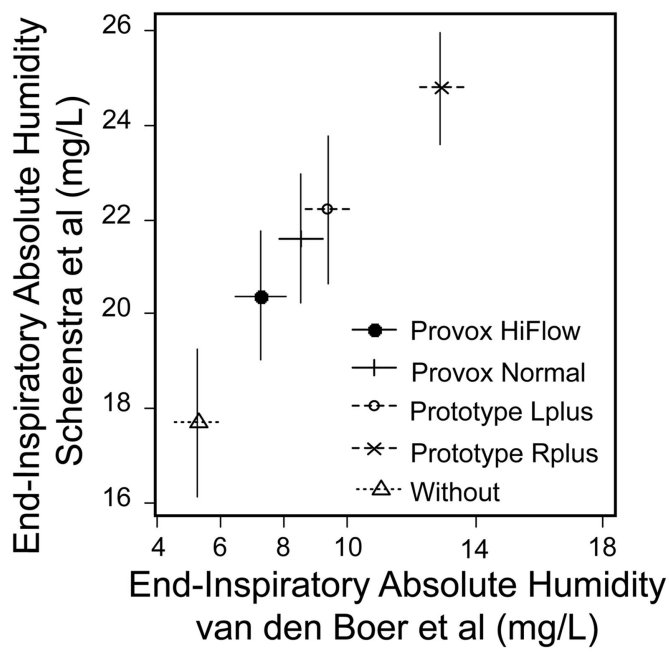

Fig. 7. End-inspiratory absolute humidity $\left(\mathrm{AH}_{\text {insp }}\right)$ values from the present study versus those from the study by Scheenstra et al ${ }^{6}$ (see Table 1) $\left(R^{2}=0.98\right)$. The bars indicate the standard errors. ${ }^{10}$

As can be seen in Figure 7, the $\mathrm{AH}_{\text {insp }}$ as measured in one volunteer correlates well with the in vivo intratracheal $\mathrm{AH}_{\text {insp }}$ measurements in a group of laryngectomized patients $\left(\mathrm{R}^{2}=0.98\right)$. It should be noted that the in vivo curve is shifted upward by about $14 \mathrm{mg} / \mathrm{L}$. This shift represents the HME effect of the upper part of the trachea, since the measurements in the laryngectomized patients were performed $1 \mathrm{~cm}$ inside the trachea. In contrast, the additional HME effect from the short distal tube in the test configuration in the present study is only minor, as can be seen in Figure 6, where the $\mathrm{AH}_{\text {insp }}$ without HME almost immediately and completely reaches the ambient humidity value.

Both the weight changes and the $\mathrm{AH}_{\text {insp }}$ values result in the same ranking levels for the 4 tested HMEs (see

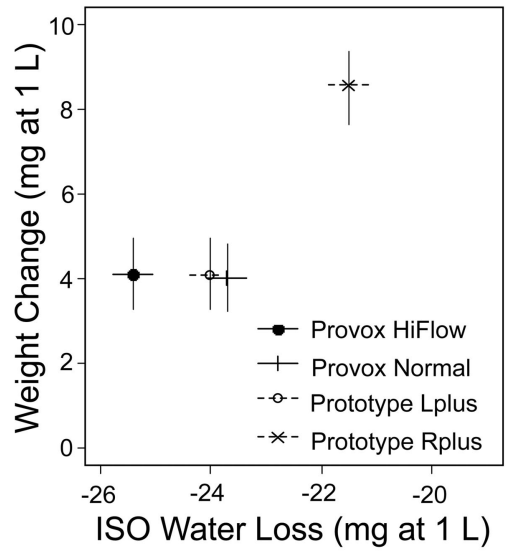

Fig. 8. Weight change of the heat and moisture exchangers in the present study versus water loss according to the International Organization for Standardization (ISO) specifications (see Table 1) $\left(R^{2}=0.77\right)$. The vertical bars show the standard deviations of the weight change; the standard deviations of the ISO values are not known. The ISO values are transformed to negative values to optimize the visual comparison.

Table 2), with the prototype Rplus being significantly better than the Provox Normal. This result matches that reported by Scheenstra et al (see Fig. 9)..$^{15}$

Comparing Figure 5 and 6 (weight change and $\mathrm{AH}_{\text {insp }}$ as a function of breathing volume, respectively), it is interesting that the curves in these figures show a very different shape. The $\mathrm{AH}_{\text {insp }}$ (see Fig. 6) decays exponentially, similar to previously described in vivo $\mathrm{AH}_{\text {insp }}$ measurements. ${ }^{6,13,15}$ Weight change (see Fig. 5) increases linearly for small volumes and then levels off. This difference can be understood qualitatively as follows. The difference in $\mathrm{AH}_{\text {insp }}$ with $\mathrm{HME}$ versus without HME represents the amount of water that is evaporated from the HME. For small volumes the difference in $\mathrm{AH}_{\text {insp }}$ with $\mathrm{HME}$ versus 


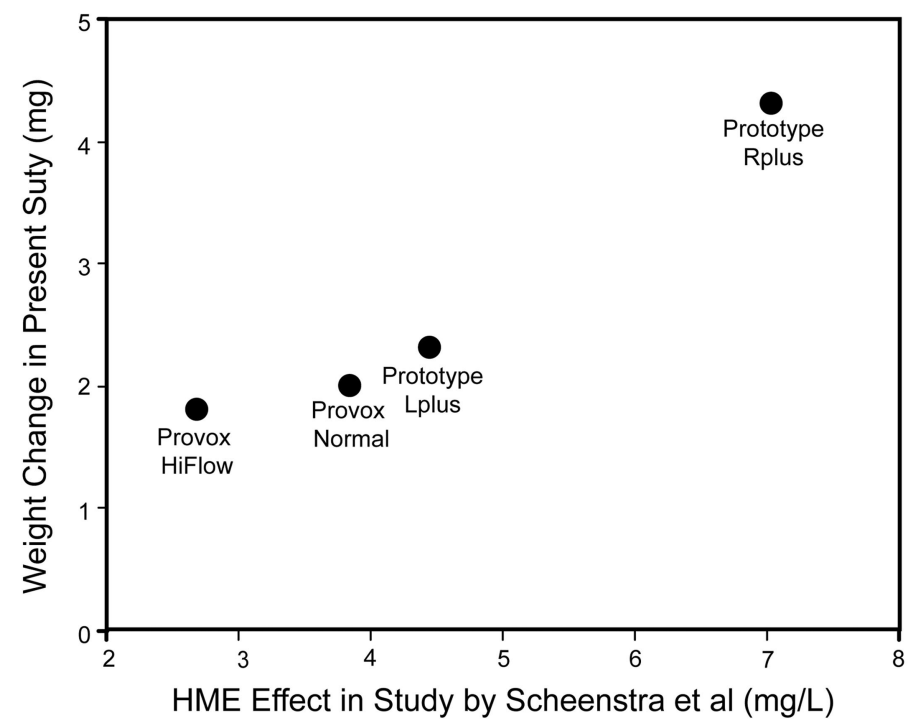

Fig. 9. Weight change of the heat and moisture exchangers (HMEs) in the present study versus HME effect (absolute humidity with versus without HME) in the in vivo study by Scheenstra et al. ${ }^{6}$

without HME is relatively large (see Fig. 6), so the HME weight changes quickly (see Fig. 5). For larger volumes the constant, but small, $\mathrm{AH}_{\text {insp }}$ difference causes a slower weight change with increasing volume. This qualitative description is quantified in the supplementary materials at http://www.rcjournal.com.

The correlation between weight change at $1.0 \mathrm{~L}$ and water loss using the ISO standard technique (see Fig. 8, $\mathrm{R}^{2}=0.77$ ) is smaller than the correlation between weight change at $0.5 \mathrm{~L}$ and in vivo measurements (see Fig. 7, $\mathrm{R}^{2}=0.98$ ). In particular, the weight change at $1.0 \mathrm{~L}$ with the Provox HiFlow is unexpectedly high, compared to the ISO value. The measurements at high volumes may be less reliable due to the use of a standard spirometer suitable for at-rest tidal volume breathing but not intended for high air velocities. Also, it cannot be excluded that the velocity of the water exchange on the foam depends on air flow velocity, which could also be an explanation for the difference between the volunteers during forced breathing.

The repeatability of the measurements on different samples of the Provox Normal exhibited no statistical differences between these samples. Furthermore, the measurements with the volunteers showed that the inter-individual variation is smaller than the significant differences between the Rplus and the other HMEs. This is in agreement with Scheenstra et al, ${ }^{15}$ who found that the inter-individual variability in patients is small. Combining these results, we can conclude that the impact of an HME on AH and weight changes can be measured reliably with one volunteer. Only the weighing measurement error limits the power of this ex vivo method, as, for instance, can be seen from the cluster of Provox Normal measurements at tidal breathing in Figure 5. In Table 2 all the differences of the
$\mathrm{AH}_{\text {insp }}$ values compared to the Provox Normal values are significant, but for weight only the Rplus was significantly different from the Provox Normal.

The advantage of this ex vivo weighing method is that it is simple to perform with a balance (accuracy of $0.1 \mathrm{mg}$ or better) and a spirometer (note that the humidity sensor in the T-tube only was needed to compare the test results with earlier in vivo measurements). The requirements for reliable measurements include preparing the HME to equilibrium humidity saturation, careful and clean handling of the HME, and rapid measuring and placement of the HME in a box that prevents evaporation. The ambient humidity should be low, since at high ambient humidity the HME will hardly collect water (see equations 1 and 2). Body temperature should be monitored to exclude fever in the volunteer. Also, the $\mathrm{AH}_{\mathrm{amb}}$ measurements (or relative humidity and temperature) are required to normalize the results by applying equations 1 and 2 .

This ex vivo weighing of water exchange of HMEs is a reliable method to measure HME performance, without the need for complex technology, and without the additional in vivo problems such as oversaturation of the fast humidity sensor by condensation or sputum. It enables fast measurement of the performance of various commercially available HMEs for tracheostomy application and, in addition to clinical data obtained from feasibility studies, is directly useful for medical professionals to obtain information about the performance of different types and newly designed HMEs. It also might be useful for developers of HMEs.

Finally, water retention in the HME (more is better) measured under human breathing circumstances is more intuitive, and might be better understandable for medical 


\section{A Novel, Simplified Ex Vivo Method for Measuring Water Exchange Performance}

professionals than is the ISO water-loss standard (a higher value means a less effective HME). In summary, this ex vivo weighing method is the "missing link" between the existing in vitro, lung-model data and in vivo data from patients.

\section{Conclusions}

This study presents a new and straightforward ex vivo method to measure HME performance by weighing the HME at the end of inspiration and the end of expiration, independent of complex technology. The results strongly correlate with previous in vivo measurements and are similar to in vitro data, using the ISO 9360-2:2001 standard equipment.

\section{REFERENCES}

1. Hartl DM, Ferlito A, Brasnu DF, Langendijk JA, Rinaldo A, Silver $\mathrm{CE}$, et al. Evidence-based review of treatment options for patients with glottic cancer. Head Neck 2011;33(11):1638-1648.

2. Hilgers FJ, Ackerstaff AH, Aaronson NK, Schouwenburg PF, van Zandwijk N. Physical and psychosocial consequences of total laryngectomy. Clin Otolaryngol Allied Sci 1990;15(5):421-425.

3. Jones AS, Young PE, Hanafi ZB, Makura ZG, Fenton JE, Hughes JP. A study of the effect of a resistive heat moisture exchanger (Trachinaze) on pulmonary function and blood gas tensions in patients who have undergone a laryngectomy: a randomized control trial of 50 patients studied over a 6-month period. Head Neck 2003; 25(5):361-367.

4. Hilgers FJ, Aaronson NK, Ackerstaff AH, Schouwenburg PF, van Zandwikj N. The influence of a heat and moisture exchanger (HME) on the respiratory symptoms after total laryngectomy. Clin Otolaryngol Allied Sci 1991;16(2):152-156.

5. Scheenstra RJ, Muller SH, Vincent A, Ackerstaff AH, Jacobi I, Hilgers FJ. Short-term endotracheal climate changes and clinical effects of a heat and moisture exchanger with an integrated electrostatic virus and bacterial filter developed for laryngectomized individuals. Acta Otolaryngol 2010;130(6):739-746.

6. Scheenstra RJ, Muller SH, Vincent A, Ackerstaff AH, Jacobi I, Hilgers FJ. A new heat and moisture exchanger for laryngectomized patients: endotracheal temperature and humidity. Respir Care 2011; 56(5):604-611.

7. Ackerstaff AH, Hilgers FJ, Aaronson NK, Balm AJ, van Zandwijk N. Improvements in respiratory and psychosocial functioning following total laryngectomy by the use of a heat and moisture exchanger. Ann Otol Rhinol Laryngol 1993;102(11):878-883.
8. Bien S, Okla S, As-Brooks CJ, Ackerstaff AH. The effect of a heat and moisture exchanger (Provox HME) on pulmonary protection after total laryngectomy: a randomized controlled study. Eur Arch Otorhinolaryngol 2010;267(3):429-435.

9. Dassonville O, Merol JC, Bozec A, Swierkosz F, Santini J, Chais A, et al. Randomised, multi-centre study of the usefulness of the heat and moisture exchanger (Provox HME) in laryngectomised patients. Eur Arch Otorhinolaryngol 2011;268(11):1647-1654.

10. International Standards Organization. Anaesthetic and respiratory equipment - heat and moisture exchangers (HMEs) for humidifying respired gases in humans. Part 1: HMEs for use with minimal tidal volume of $250 \mathrm{~mL}$. Geneva: ISO; 9360-1:2000.

11. International Standards Organization. Anaesthetic and respiratory equipment—heat and moisture exchangers (HMEs) for humidifying respired gases in humans. Part 2: HMEs for use with tracheostomized patients having minimal tidal volume of $250 \mathrm{~mL}$. Geneva: ISO; 9360-2:2001

12. Keck T, Durr J, Leiacker R, Rettinger G, Rozsasi A. Tracheal climate in laryngectomees after use of a heat and moisture exchanger. Laryngoscope 2005;115(3):534-537.

13. Zuur JK, Muller SH, de Jongh FH, van der Horst MJ, Shehata M, van Leeuwen J, et al. A newly developed tool for intra-tracheal temperature and humidity assessment in laryngectomized individuals: the Airway Climate Explorer (ACE). Med Biol Eng Comput 2007;45(8):737-745.

14. McRae RD, Jones AS, Young P, Hamilton J. Resistance, humidity and temperature of the tracheal airway. Clin Otolaryngol Allied Sci 1995;20(4):355-356.

15. Scheenstra RJ, Muller SH, Hilgers FJ. Endotracheal temperature and humidity in laryngectomized patients in a warm and dry environment and the effect of a heat and moisture exchanger. Head Neck 2011; 33(9):1285-1293.

16. Rathgeber J, Kahle G, Schulze T, Züchner K. [Rapid measurement of water vapor partial pressure at the saturation point with a new hybrid humidity sensor]. Biomed Tech (Berl) 2000;45(10):288-292. Article in German.

17. Dow Chemical. The calcium chloride handbook, a guide to properties, forms, storage and handling. http://www.scribd.com/doc/ 49373766/Calcium-Chloride-Handbook. Accessed June 26, 2013.

18. Wilkes AR. The moisture-conserving performance of breathing system filters in use with simulated circle anaesthesia breathing systems. Anaesthesia 2004;59(3):271-277.

19. Zuur JK, Muller SH, Vincent A, Sinaasappel M, de Jongh FH, Hilgers FJ. Assessment of tracheal temperature and humidity in laryngectomized individuals and the influence of a heat and moisture exchanger on tracheal climate. Head Neck 2008;30(8):1072-1082.

20. Scheenstra RJ, Muller SH, Vincent A, Sinaasappel M, Hilgers FJ. Influence of breathing resistance of heat and moisture exchangers on tracheal climate and breathing pattern in laryngectomized individuals. Head Neck 2010;32(8):1069-1078.

This article is approved for Continuing Respiratory Care Education credit. For information and to obtain your CRCE

(free to AARC members) visit www.rcjournal.com

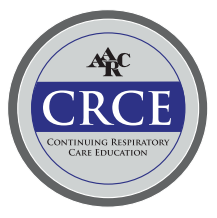

